\title{
Preoperative and postoperative features of non-functioning pituitary adenomas: a single center experience
}

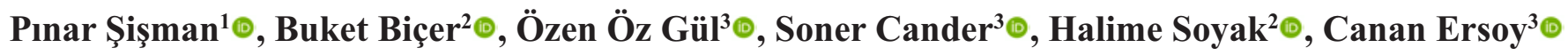 \\ ${ }^{1}$ Department of Endocrinology and Metabolism, Medicana Hospital, Bursa, Turkey \\ ${ }^{2}$ Department of Internal Medicine, Bursa Uludağ University School of Medicine, Bursa, Turkey \\ ${ }^{3}$ Department of Endocrinology and Metabolism, Bursa Uludă̆ University School of Medicine, Bursa, Turkey
}

DOI: $10.18621 /$ eurj.415248

\begin{abstract}
Objectives: The main purposes of surgical treatment for non-functioning pituitary adenomas are removal of the pressure on the surrounding structures, especially the hypophyseal gland and visual tissue, and the normalization of hypophyseal functions. In our study, we retrospectively reviewed postsurgical follow-up of patients with non-functioning pituitary adenoma treated at our institution in a period of 15 years of monitoring and evaluated surgical success, complication rate and recurrence rates in accordance with the literature.

Methods: This study included 55 patients who had undergone surgery between 2000 and 2014 and who were followed-up postoperatively at our center. Preoperative and postoperative anterior pituitary hormones, complete resection and recurrence and also postoperative recovery of endocrinological and ophthalmological functions were statistically evaluated using file data of the patients.

Results: There were $33(60 \%)$ males and $22(40 \%)$ females. It was observed that the adenoma caused pressure on the optic chiasm in 11 patients and infiltrated cavernous sinus in 9 patients. Postoperative mean follow-up was $75.14 \pm 43.01$ months. Seventeen $(30.9 \%)$ patients had recurrence after complete resection. Postoperative persistence and deterioration rates were $12.2 \%$ and $26.6 \%$ in adrenal insufficiency, $12.2 \%$ and $26.6 \%$ in central hypothyroidism, respectively, while $12.2 \%$ worsening in central hypogonadism. Ophthalmologic findings were resolved in $62.5 \%$ of patients and persisted in $37.5 \%$ of the patients.

Conclusions: The adenoma size and experience of the surgeon in non-functioning pituitary adenomas are the most important factors affecting surgical success. We recommend that operations should be performed in experienced centers, preoperative and postoperative endocrinological evaluations and long-term follow-up should be done.
\end{abstract}

Keywords: Pituitary adenoma, non-functioning, surgery

Received: April 17, 2018; Accepted: September 29, 2018; Published Online: June 30, 2019

$\mathrm{T}$ he prevalence of pituitary adenomas ranges from 1 in 865 adults to 1 in 2688 adults and $15-54 \%$ of all pituitary adenomas constitute non-functioning pituitary adenomas (NFPA) [1]. In a study of Swedish Pituitary Registry, it is observed that NFPA was the most common cause of pituitary adenomas (54\%), followed by prolactinomas (32\%), acromegaly (9\%), Cushing's disease (4\%), thyroid stimulating hormone (TSH) secretory pituitary adenomas $(0.7 \%)$; respectively [2]. Of the pituitary adenomas detected in au-

Address for correspondence: Pınar Şişman, MD., Medicana Hospital, Department Endocrinology and Metabolism, Bursa, Turkey E-mail: drpinarsisman@gmail.com 
topsy series, $40 \%$ constitute NFPA [3].

Because of NFPA do not cause excessive hormone secretion, patients are often diagnosed when the symptoms due to the pressure effect of the mass are under investigation [4]. The most important symptoms and findings are the bitemporal hemianopsy that develops due to the mass effect on the surrounding tissues such as optic chiasm and hypophyseal insufficiency in varying degrees due to pressure-dependent destruction of the hypophyseal cells [5]. Hemorrhagic infarction (hypophyseal apoplexy) in the tumor can be observed as an initial finding in NFPA and causes severe headache, visual impairment and hypopituitarism due to sudden intra-sella pressure increase $[6,7]$. However, with the increasing use of imaging modalities in recent years, NFPA can be detected in the asymptomatic period. Hypophyseal lesions detected on cranial images without symptoms are called hypophyseal incidentalomas. Lesions smaller than $1 \mathrm{~cm}$ are classified as microinsidentalomas and lesions larger than $1 \mathrm{~cm}$ are classified as macroinsidentalomas [8].

Surgery is recommended in symptomatic patients with impaired vision in the ophthalmologic examination or hypophyseal insufficiency in the evaluation of the hypophyseal functions [7]. Nevertheless, in a retrospective evaluation of surgical outcomes in asymptomatic and symptomatic NFPA, Messerer et al. [9] found that total resection success of adenoma in asymptomatic patients was statistically significantly higher ( $82 \%$ vs. $58 \%$ ) than symptomatic patients [9]. In the same study, the risk of developing postoperative hormonal insufficiency was found to be 10 times lower in asymptomatic patients. In asymptomatic NFPA, surgical decision is recommended to be based on tumor size, age of the patient, localization of the tumor, and accompanying comorbidities [9].

The main purpose of surgical treatment is removal of the pressure on the peripheral structures, especially the hypophyseal gland and visual tissues, normalization of hypophyseal function and prevention of tumor recurrence [10]. However, surgical success is primarily associated with preoperative adenoma size [11].

In our study, we retrospectively reviewed postsurgical follow-up of patients with NFPA at our institution in a period of 15 years of monitoring and evaluated surgical success, complication rate and recurrence rates in the view of the literature.

\section{METHODS}

This study included 55 patients ( 33 males and 22 females) who had undergone surgery due to NFPA between 2000 and 2014 and who were followed-up postoperatively at our center. The complaints of the patients at the time of first admission were evaluated using the patients' file data. In preoperative endocrinological examination prolactin, growth hormone $(\mathrm{GH})$, insulin like growth factor-1 (IGF-1), adrenocorticotropic hormone (ACTH), cortisol, TSH, free T4 (fT4), follicle-stimulated hormone (FSH), luteinizing hormone (LH), estradiol in women and testosterone levels in men were evaluated. Acromegaly was excluded in patients with presence of clinical findings of acromegaly and high serum IGF-1 levels based on age and sex. Cushing disease and prolactinoma were also excluded in patients with clinical findings and high serum ACTH, cortisol and prolactin, respectively. The age, sex, and postoperative follow-up period of the patients included in the study were analyzed using file data. The presence of hypopituitarism was also investigated by evaluating the preoperative pituitary hormones of the patients. In preoperative hormonal evaluation morning serum cortisol $<3 \mu \mathrm{g} / \mathrm{dl}$, accompanied by low or inappropriate normal ACTH levels were defined as central adrenal insufficiency. Adrenal insufficiency was excluded if serum cortisol was $\geq 18 \mu \mathrm{g} / \mathrm{dl}$ and low dose ACTH stimulation test was performed between $3-18 \mu \mathrm{g} / \mathrm{dl}$ of cortisol. Adrenal insufficiency was excluded if the serum cortisol level was $\geq 18 \mu \mathrm{g} / \mathrm{dl}$ at one of the $0,30,60$ and 90 . minutes values after $1 \mu \mathrm{g}$ ACTH stimulation. TSH and fT4 levels were evaluated in the diagnosis of central hypothyroidism. If sT4 level was low, TSH was low or inappropriate, central hypothyroidism was diagnosed. Concomitant low testosteron in men and low eostrogen in women with low or inappropriate normal FSH and LH levels were defined as central hypogonadism. Panhypopituitarism was assessed as the insufficiency of all pituiatry hormones.

Preoperative sella magnetic resonance imaging (MRI) was used to assess the diameter of adenoma based on the longest diameter. The presence of extracellular expansion, cavernous sinus invasion and compression of optic chiasm were examined on MRI. 
Table 1. Characteristics and follow-up results of patients $(n=55)$

\begin{tabular}{lc}
\hline Characteristics & Data \\
\hline Gender, n (\%) & $22(40 \%)$ \\
$\quad$ Female & $33(60 \%)$ \\
$\quad$ Male & $54.27 \pm 10.75(30-75)$ \\
Age (years) & \\
mean \pm SD (range) & $28.91 \pm 9.67(11-52)$ \\
Preoperative adenoma size (mm) & \\
mean \pm SD (range) & \\
Postoperative complete resection, $\mathrm{n}$ & $39(70.9 \%)$ \\
$\quad$ Yes & $16(29.1 \%)$ \\
$\quad$ No & $75.14 \pm 43.01(34-233)$ \\
Postoperative follow-up (month) & \\
mean \pm SD (range) & \\
Postoperative recurrence, $\mathrm{n}(\%)$ & $17 / 39(43.6 \%)$ \\
$\quad$ Yes & $22 / 39(46.4 \%)$ \\
$\quad$ No &
\end{tabular}

The presence of visual field loss was evaluated in preoperative visual field examination using file data of all patients. Patients who had lost preoperative visual field were reevaluated postoperatively and the improvement and persistence rates of visual impairment were recorded. Pathological immunohistochemical examination of postoperative material was examined. In the early postoperative period, all patients were examined for diabetes insipidus (DI). Detection of polyuria ( $>31 \mathrm{t} / 24 \mathrm{~h})$ and low urine osmolality $(<300 \mathrm{mOsm})$ in the presence of normal or high serum sodium levels was interpreted as DI. Patients who developed DI were reevaluated in the follow-up and temporary or permanent DI were investigated. Postoperative hypopituitarism development, postoperative complete resection rates and recurrence rates were analyzed.

\section{Statistical Analysis}

Statistical evaluations were performed on IBM SPSS version 21 (IBM Acquires SPSS Inc., Somers, NY, USA). Frequency values and/or descriptive statistics were calculated for variables that showed clinical characteristics of patients. The descriptive statistics of the continuous variables of the patients are given as the mean and standard deviation in the appropriate data or as the minimum-maximum.

\section{RESULTS}

There were $33(60 \%)$ males and $22(40 \%)$ females. The mean age was $54.27 \pm 10.75$ years (Table 1). All patients underwent pituitary surgery due to macroadenoma. Preoperative complaints of patients are given in Table 2. MRI and ophthalmologic examination was performed in 47 patients. The mean

Table 2. Preoperative clinical findings of patients $(n=55)$

\begin{tabular}{lc}
\hline Clinical Findings & Data \\
\hline Visual field disturbance & $30(54.5 \%)$ \\
Headache & $20(36.4 \%)$ \\
Loss of vision & $7(12.7 \%)$ \\
Diplopia & $2(3.6 \%)$ \\
Fatique & $13(23.6 \%)$ \\
Dizziness & $3(5.4 \%)$ \\
Nause-vomiting & $2(3.6 \%)$ \\
Diminished libido & $7(12.7 \%)$ \\
Menstrual irregularities & $3(5.4 \%)$ \\
Ptosis & $1(1.8 \%)$ \\
Tinnitus & $2(3.6 \%)$ \\
Weight gain & $1(1.8 \%)$ \\
\hline
\end{tabular}


Table 3. Preoperative MRI and ophthalmological data of patients $(n=47)$

\begin{tabular}{lcc}
\hline MRI & No extrasellar extansion & $12(25.5 \%)$ \\
& Suprasellar extansion & $35(74.5 \%)$ \\
& Infrasellar extansion & $5(10.6 \%)$ \\
& Compression of optic chiasm & $11(23.4 \%)$ \\
Ophthalmologic & Invasion of cavernous sinus & $9(19.1 \%)$ \\
examination & Normal & $10(21.3 \%)$ \\
& Temporal hemianopsia & $2(4.3 \%)$ \\
& Bitemporal hemianopsia & $24(51.0 \%)$ \\
& Quadranopsia & $2(4.3 \%)$ \\
& Concentric narrowing & $5(10.6 \%)$ \\
\hline
\end{tabular}

MRI = Magnetic rezonance imaging. MRI and ophthalmologic examination was performed in 47 patients.

adenoma size in preoperative sella MRI was $28.91 \pm$ 9.67 (11-52) mm. Sellar localization without expansion in MRI was observed in 12 (25.5\%) patients. Suprasellar expansion was observed in 35 $(74.5 \%)$ patients and both supra- and infrasellar expansion in $5(10.6 \%)$ patients. In $11(23.4 \%)$ patients, adenoma caused pressure on the optic chiasm and in $9(19.1 \%)$ patients adenoma infiltrated cavernous sinuses. In the evaluation of the preoperative visual field, the visual field was normal in $10(21.3 \%)$ patients, while the remaining patients had visual field defects (Table 3). Central adrenal insufficiency was present in 6 patients $(10.9 \%)$, central hypothyroidism in 7 patients $(12.7 \%)$, central hypogonadism in 1 patient $(1.8 \%)$ and DI in 2 patients $(3.6 \%)$ in preoperative endocrinological evaluation. None of patients had preoperative panhipopituitarism. Postoperative mean follow-up was $75.14 \pm 43.01$ (34233) months.

Among 55 patients included in our study 54 were treated surgically at our center and one patient had a surgery at a different center. In $51(94.4 \%)$ patient the surgical method was chosen to be transsphenoidal surgery and $3(5.6 \%)$ patient underwent transcranial surgery in our center. In pathological immunohistochemical evaluation positive staining was not detected in 13/48 (25.5\%) patients, whereas FSH positivity in $19(34.5 \%)$ patients, LH positivity in $12(21.8 \%)$ patients, ACTH positivity in $6(10.9 \%)$ patients, prolactin positivity in $5(9.0 \%)$ patients, $\mathrm{TSH}$ positivity in $5(9.0 \%)$ patients and GH positivity in 1 $(1.8 \%)$ patient were detected (Table 4$)$. Complete resection was achieved in 39 patients (70.9\%) postoperatively, while residual adenoma was detected in 16 patients $(29.1 \%)$ in pituitary MRI performed at 3 months postoperatively (Table 1). Two patients did not undergo postoperative MRI evaluation at the third month. In the patients who had complete resection, recurrence was seen in $17 / 39$ patients $(43.6 \%$ ) (see Table 1). In the follow-up, 12 patients had 2nd operation and 2 patients had 3rd operation (Table 5). All the patients included in the study were examined for the development of electrolyte disturbances, especially DI during the postoperative hospitalization. $12(21.8 \%)$ patients had postoperative DI. Six (10.9\%) patients were observed to develop permanent DI. Sixteen $(29.0 \%)$ patients had central adrenal

Table 4. Immunohistochemical staining patterns of adenomas

\begin{tabular}{lc}
\hline FSH & $19(34.5 \%)$ \\
LH & $12(21.8 \%)$ \\
GH & $1(1.8 \%)$ \\
ACTH & $6(10.9 \%)$ \\
TSH & $5(9.0 \%)$ \\
Prolactin & $5(9.0 \%)$ \\
Negative & $13(27.1 \%)$ \\
\hline
\end{tabular}

Immunohistochemical staining was performed in 48 patints. More than one immunohistochemical staining positivity can be found in adenomas. FSH = follicle-stimulated hormone, $\mathrm{LH}=$ luteinizing hormone, $\mathrm{GH}=$ growth hormone, $\mathrm{ACTH}=$ adrenocorticotropic hormone, $\mathrm{TSH}=$ thyroid stimulating hormone 
Table 5. Operation techniques of the patients

\begin{tabular}{cccc}
\hline & Male & Female & Total \\
\hline First surgery $(\mathbf{n}=\mathbf{5 4})$ & & & \\
TSS & $31(93.9 \%)$ & $20(95.2 \%)$ & $51(94.4 \%)$ \\
TCS & $2(6.1 \%)$ & $1(4.8 \%)$ & $3(5.6 \%)$ \\
Second surgery $(\mathbf{n}=\mathbf{1 2})$ & & & \\
TSS & $5(62.5 \%)$ & $3(75 \%)$ & $8(66.7 \%)$ \\
TCS & $3(37.5 \%)$ & $1(25 \%)$ & $4(33.3 \%)$ \\
Third surgery $(\mathbf{n}=\mathbf{2})$ & $1(100 \%)$ & $1(100 \%)$ & $2(100 \%)$ \\
TSS & - & - & - \\
TCS & &
\end{tabular}

TSS $=$ Transsphenoidal surgery, TCS $=$ Transcranial surgery

Table 6. Data of preoperative and postoperative endocrinological and ophthalmological findings

\begin{tabular}{|c|c|c|}
\hline \multirow{3}{*}{$\begin{array}{l}\text { Adrenal insufficiency } \\
\qquad(\mathrm{n}=49)\end{array}$} & None $^{\mathrm{a}}$ & $30(61.2 \%)$ \\
\hline & Persistence $^{\mathrm{b}}$ & $6(12.2 \%)$ \\
\hline & Recovery $^{\mathrm{c}}$ & 0 \\
\hline \multirow{5}{*}{$\begin{array}{l}\text { Central hypothyroidism } \\
\qquad(\mathrm{n}=49)\end{array}$} & Impairment $^{\mathrm{d}}$ & $13(26.6 \%)$ \\
\hline & None & $29(59.1 \%)$ \\
\hline & Persistence & $6(12.2 \%)$ \\
\hline & Recovery & $1(2.1 \%)$ \\
\hline & Impairment & $13(26.6 \%)$ \\
\hline \multirow{4}{*}{$\begin{array}{c}\text { Central hypogonadism } \\
\qquad(\mathrm{n}=49)\end{array}$} & None & $42(85.7 \%)$ \\
\hline & Persistence & 0 \\
\hline & Recovery & $1(2.1 \%)$ \\
\hline & Impairment & $6(12.2 \%)$ \\
\hline \multirow{3}{*}{$\begin{array}{l}\text { Oftalmologic } \\
\qquad \begin{array}{r}\text { (preop.) }(n=47) \\
(\text { postop })(n=16)\end{array}\end{array}$} & None $e^{\mathrm{e}}$ & $10 / 47(21.3 \%)$ \\
\hline & Persistence & $6 / 16(37.5 \%)$ \\
\hline & Recovery & $10 / 16(62.5 \%)$ \\
\hline
\end{tabular}

Preop. $=$ Preoperative, Postop. $=$ Postoperative.${ }^{\text {a }}$ There are no pathologic findings in preoperative and postoperative examination. ${ }^{\mathrm{b}}$ There are pathologic findings in preoperative and postoperative examination. ${ }^{\mathrm{c}}$ There are pathologic findings in preoperative examination and there are no pathologic findings in postoperative examination. ${ }^{\mathrm{d}}$ There are no pathologic findings in preoperative examination and there are pathologic findings in postoperative examination. ${ }^{\mathrm{e}}$ There are no pathologic findings in preoperative examination.

insufficiency, $16(29.0 \%)$ patients had central hypothyroidism, $3(5.4 \%)$ patients had central hypogonadism and $6(10.9 \%)$ patients had panhypopituitarism. The rates of improvement, persistence and deterioration of endocrinological and ophthalmological findings at postoperative evaluation are given in Table 6 .

Gammaknife was given to $916.3 \%$ ) patients (and conventional radiotherapy was given to $3(5.4 \%)$ patients in postoperative period. After gammaknife and conventional radiotherapy treatments, central hypothyroidism was observed in 1 (8.3\%)patient, central hypothyroidism and adrenal insufficiency in 1 $(8.3 \%)$ patient, central hypothyroidism and hypogonadism in $1 \quad(8.3 \%)$ patient and panhypopituitarism was observed in $1(8.3 \%)$ patient. 


\section{DISCUSSION}

NFPA constitutes approximately one third of all pituitary adenomas. In a recent autopsy study, adenoma frequency was found to be $10.5 \%$ and $35 \%$ of adenomas were observed to be composed of NFPA. In this study, the median tumor diameter was found to be $1.6 \mathrm{~mm}$, and macroadenomas were detected in only two patients [3]. Our study included patients with nonfunctional pituitary macroadenomas with a mean tumor diameter of $28.91 \pm 9.67 \mathrm{~mm}$. The mean age at diagnosis at NFPA is around 50-55 years and the frequency is slightly higher in males $(56.7 \%)$ [18]. In our study, the frequency of male gender was found to be more frequent $(60 \%)$ and the mean age of diagnosis was $54.27 \pm 10.75(30-75)$ years.

NFPA is rarely seen as a component of multiple endocrine neoplasia-1 (MEN-1) and familial idiopathic pituitary adenoma (FIPA) [12]. Atypical pituitary adenomas and pituitary carcinomas are characterized by Ki-67 index $\geq 3$ and p53 protein positivity and are resistant to conventional treatments. Pituitary carcinomas also causecerebrospinal and/or systemic metastases. While atypical pituitary adenomas are observed at $2.7 \%$, the incidence of carcinomas $(0.1-0.2 \%)$ is very low [13]. In our study atypical pituitary adenomas were present in $3(5.4 \%)$ patients and no pituitary carcinoma was found.

According to the structural and immunohistochemical characteristics, NFPA are divided into 3 groups (gonadotropic adenomas, null cell adenomas and oncocytomas). Gonadotropic adenomas show positive staining with FSH, LH or subunits, while null cell adenomas and oncocytomas are not stained. These three groups constitute $85 \%$ of all NFPA, while the remaining $15 \%$ constitute silent adenomas, which are immunohistochemically positive and do not cause any symptom $[14,15]$. In our study, immunohistochemical evaluation was performed in 48 patients. Immunohistochemical staining was negative in $13(27 \%)$ patients. Gonadotropic adenomas were detected in $25(52 \%)$ patients while silent adenomas were detected in $10(21 \%)$ patients.

NFPA are usually diagnosed by symptoms such as headache, visual disturbances, cranial nerve palsy, and hypopituitarism, which are caused by mass pressure on the surrounding tissues [16]. Depending on the mass effect of adenoma, headache may occur in $25 \%$ of the macroadenoma patients, most likely due to the expansion of the sella. Suprasellar enlargement in the tumor leads to pressure on the optic chiasm, leading to visual field defects, primarily bitemporal hemianopsy. Prolonged compression of the optic nerve can lead to atrophy of the nerve resulting in decreased visual acuity. Extension of the adenoma to the lateral lobe and invasion of the cavernous sinuses does not always result in clinical signs, but may result in pitosis, ophthalmoplegia, and diplopia, leading to involvement in the 4th and 6th nerves, primarily cranial nerve 3. Rarely, parasellar enlargement can cause compression in the temporal lobe and seizure development, inferior enlargement to the sphenoid sinus may cause rhinorrhea very rarely $[12,17,18]$. Among the patients included in the study, the most common complaint was visual impairment (54.5\%) and headache (36.3\%). In MRI, compression of optic chiasm was detected in $11(23.4 \%)$ patients. Pitozis was present in $1(1.8 \%)$ patient and diplopia in 2 $(3.6 \%)$ patients. The most common findings in ophthalmologic examination were bitemporal hemianopsia $(51.0 \%)$ and concentric narrowing $(10.6 \%)$ in the visual field. No ophthalmologic problem was found in $21.3 \%$ of the patients.

Pituitary apoplexy is a rare condition characterized by sudden hemorrhage into the pituitary macroadenoma. It causes severe headache and impaired vision. It can be developed spontaneously however may be associated with pregnancy, surgery and anticoagulant use $[19,20]$. Pituitary apoplexy was not observed in the patients included in our study.

The purpose of treatment in patients with symptoms is to provide rapid decompression and relieve symptoms [18]. Successful total surgical resection of NFPA can be achieved in the literature with a wide spectrum, varying between $18-81 \%$ [21, 22]. In our study, total surgical resection was observed in $39(73.5 \%)$ of the 53 patients whose evaluation was performed.

Radiotherapy may be effective in residual tumor patients with postoperative growth potential. Radiotherapy is recommended to patients which has a tendency to grow in post-operative follow-up, residual tissue remaining and life expectancy is more than 10 years [23]. However, there is a risk of hypopituitarism in the long term. It may also lead to visual deterioration, secondary brain tumor development, 
seizure and possibly neurocognitive and neuropsychological impairment [16, 24]. In our study, $9(16.3 \%)$ patients were treated with gammanife and $3(5.4 \%)$ patients were treated with radiotherapy.

Total or partial improvement is seen in $80-90 \%$ of cases after surgery. This improvement continues up to 1 year after surgery. The urgency of the surgery is related to the severity of visual impairment $[25,26]$. In our study, preoperative ophthalmological evaluation was performed in 48 patients and pathological findings were found in $38(79.2 \%)$ of the patients. At postoperative 3 rd month, only 16 of 38 patients had reevaluation and $10(62.5 \%)$ patients had total or partial healing and $6(37.5 \%)$ patients had persistent findings. It is thought that the low number of patients with post-operative evaluation may be due to insufficient file records.

$30-40 \%$ of macroadenomas are accompanied by partial or total hypophyseal insufficiency and there is a risk of developing $12 \%$ hypophyseal insufficiency every year in macroadenomas [27, 28]. Loss of hypophyseal functions can be explained by the expanding adenoma leading to pressure on pituitary stalk and portal veins [29]. The development of hypopituitarism occurs in GH, FSH/LH, TSH and ACTH hormones respectively. Clinical findings are associated with the type and severity of hormonal deficiencies and may be nonspecific [30]. In the patients included in our study, TSH deficiency was the most prominent findings, followed by ACTH and FSH/LH deficiency. None of patients had preoperative panhypopituitarism.

In cases with preoperative hypophyseal insufficiency, surgery achieves to lead an improvement in the anterior pituitary hormones in $30 \%$ of the patients during one year follow-up after surgery [9]. The risk of postoperative hypophyseal insufficiency is approximately 10\% [31]. Pituitary insufficiency develops due to the resection or injury of anterior pituitary or stalk. Risk is variable due to the adenoma size, extent of resection and the experience of the surgeon. Stalk injury or resection results in DI. Temporary DI is approximately $10-20 \%$ while permanent DI is $2-7 \%$. Surgical mortality is below $2 \%$ in experienced centers [32]. Twelve $(21.8 \%)$ of the patients included in our study had temporary DI and $6(10.9 \%)$ had persistent DI in postoperative period. According to the literature in the patients included in our study, high DI ratios can be explained by the large adenoma size and the high extracellular expansion rates.

In postoperative follow-up at 3-6. month and at 1 year pituitary MRI control is recommended [33]. Imaging is not rutinly recommended in the early postoperative period, but it may be helpful to remove the suspicion of postoperative complications and early surgical revision [34]. Unless a postoperative residual is detected, long-term follow-up of the first 5 years is recommended every year, followed by imaging at 7 , 10 and 15 years. In the presence of postoperative residue or residual doubt, it is recommended to determine the MRI control intervals in the first 5 years every year, if there is no progression in the next period, once every 2-3 years, considering the tumor diameter, distant to the optic nerve and progression suspicion [35].

Control of the anterior pituitary hormones is recommended at 3rd month postoperatively to assess possible hypopituitarism. At the same time, ophthalmologic evaluation should be performed at postoperative $3 \mathrm{rd}$ month in patients with preoperative ophthalmologic abnormalities and should be followed every 6 months until maximum improvement is achieved. Follow-up can be discontinued in patients who have no abnormalities at the first postoperative follow-up and those who do not have a residual tumor close to the optic nevre [35].

Surgical revision may be required in $30-48 \%$ of NFPA patients due to the presence of large residual tumor in the early period or progression in follow-up after transsphenoidal surgery [36]. In the series published in the literature, it was observed that in a series with 160 microadenomas, MRI showed more than $10.6 \%$ tumor growth, $6.3 \%$ tumor shrinkage and $83.1 \%$ tumor size change in a longer follow-up than 8 years. In the same period follow-up of 353 patients with macroadenoma, $24.1 \%$ of the patients had tumor size growth, $12.7 \%$ had tumor size reduction and $63.2 \%$ of the patients showed similar persistence in the tumor size [37]. In a study conducted by Losa et al. [37], postoperative recurrence was found to be lower in patients undergoing early surgery. In the present study the mean postoperative follow-up time was $75.14 \pm 43.01$ months and $43.5 \%$ of the patients had recurrence. It has been showed that the risk of mortality was higher in NPHAs than in healthy 
control. The causes of mortality were cardiovascular diseases, respiratory diseases and infections [38]. It has been alsofound that overall survival in patients with pituitary carcinomas was significantly worse than in patients with invasive pituitary adenomas [39]. In our study, no pituitary carcinoma was found.

\section{Limitations}

The retrospective nature of our study, the low number of patients and the possible deficits in patient file datas are among the limitations of our study. We believe that prospective studies with more patient numbers will provide clearer results on postoperative monitoring and follow-up of NFPAs.

\section{CONCLUSION}

As a result, NFPAs are often asymptomatic and are frequently diagnosed as incidental because of the increased imaging modalities currently available. The decision of the treatment is based on adenoma size, growth potential and presence of symptoms. Preoperative detailed endocrinological evaluation is very important in preventing complications due to operation and anesthesia. The urgency of the surgery is related to the severity of visual impairment. Adenoma size and experience of the surgeon are the most important factors affecting surgical success. Hypopituitarism may be developed in patients with normal hypophiseal functions, and also, hypopituitarism may be resolved with surgery. Operation performed in experienced centers, preoperative and postoperative endocrinological evaluation and long-term follow-up are recommended.

\section{Authorship declaration}

All authors listed meet the authorship criteria according to the latest guidelines of the International Committee of Medical Journal Editors, and all authors are in agreement with the manuscript

\section{Conflict of interest}

The author disclosed no conflict of interest during the preparation or publication of this manuscript.

\section{Financing}

The author disclosed that they did not receive any grant during conduction or writing of this study.

\section{REFERENCES}

[1] Molitch ME. Diagnosis and treatment of pituitary adenomas: a review. JAMA 2017;317:516-24.

[2] Tjörnstrand A, Gunnarsson K, Evert M, Holmberg E, Ragnarsson $\mathrm{O}$, Rosen $\mathrm{T}$, et al. The incidance rate of pituitary adenomas in western Sweden for the period 2001-2011. Eur J Endocrinol 2014;171:519-26.

[3] Buurman H, Saeger W. Subclinical adenomas in postmortem pituitaries: classification and correlations to clinical data. Eur J Endocrinol 2006;154:753- 6.

[4] Bonneville JF, Cattin F, Bonneville F. Imaging of pituitary adenomas. Presse Med 2009;38:84-91.

[5] Mello PA, Naves LA, Pereira Neto A, Oliveira EH, Ferreira IC, Araújo Júnior AS, et al. Clinical and laboratorial characterization and post-surgical follow-up of 87patients with non-functioning pituitary macroadenomas. Arq Neuropsiquiatr 2013;71:307-12.

[6] Dekkes OM, Hammer S, deKeiser RJW, Roelfsema F, Schutte PJ, Smit JW, et al. The naturel course of non-functioning pituitary macroadenomas. Eur J Endocrinol 2007;156:217-24.

[7] Greenman Y, Stern N. Non-functioning pituitary adenomas. Best Pract Res Clin Endocrinol Metab 2009;23:625-38.

[8] Freda PU, Beckers AM, Katznelson L, Molitch ME, Montori VM, Post KD, et al; Endocrine Society. Pituitary incidentaloma: an endocrine society clinical practice guideline. J Clin Endocrinol Metab 2011;96:894-904.

[9] Messerer M, Dibourg J, Raverot G, Bervini D, Berhouma M, George I, et al. Non-functioning pituitary macro-incidentalomas benefit from early surgery before becoming symptomatic. Clin Neurolo Neurosurg 2013;115:2514-20.

[10] Maartens NE, Kaye AH. Role of transcranial approachs in the treatment of sellar and suprasellar lesions. Front Horm Res 2006;34:1-28.

[11] Ferreira JE, de Mello PA, de Magalhaes AV, Botelho CH, Naves LA, Nosé V, et al. [Non-functioning pituitary adenomas: clinical features and immunohistochemistry]. Arq Neuropsiquatr 2005;63:1070-1078. [Article in Portuguese]

[12] Korbonits M, Carlsen E. Recent clinical and pathophysiological advances in non-functioning pituitary adenomas. Horm Res 2009;71 Suppl 2:123-30.

[13] Hirohata T, Ishii Y, Matsuno A. Treatment of pituitary carcinomas and atypical pituitary adenomas: a review. Neurol Med Chir (Tokyo) 2014;54:966-73.

[14] Saeger W, Lüdecke DK, Buchfelder M, Fahlbusch R, Quabbe HJ, Petersenn S. Pathohistological classification of pituitary tumors: 10 years of experience with the German Pituitary Tumor Registry. Eur J Endocrinol 2007;156:203-16.

[15] Yamada S, Ohyama K, Taguchi M, Takeshita A, Morita K, Takano K, et al. A study of the correlation between morphological findings and biological activities in clinically nonfunctioning pituitary adenomas. Neurosurgery 2007;61:580-5.

[16] Greenman Y, Stern N. Optimal managemant of non- 
functioning pituitary adenomas. Endocrine 2015;50:51-5.

[17] Caroll WR, Cohen S, Sullivan MJ. Spontaneous CSF rhinorrhea: an unusual presentation of a pituitary adenoma. Otolaryngol Head Neck Surg 1991;104:380-3.

[18] Deepak D, Daousi C, Javadpour M, MacFarlane IA. Macroprolactinomas and epilepsy. Clin Endocrinol (Oxf.) 2007;66:503-7.

[19] Nawar RN, AbdelMannan D, Selmar WR, Arafah BM. Pituitary tumor apoplex: a review. J Intensive Care Med 2008;23:75-90.

[20] Semple PL, Jane JA Jr, Laws ER Jr. Clinical relevance of precipitating factors in pituitary apoplexy. Neurosurgery 2007;61:956-61; discussion 61-2.

[21] Honneger J, Ernemann U, Psaras T, Will B. Objective criteria for successful transsfenoidal removal of suprasellar nonfunctioning pituitary adenomas. A prospective study. Acta Neurochir (Wien) 2007;149:21-9; discusssion 29.

[22] Reddy R, Cudlip S, Byrne JV, Karavitaki N, Wass JA. Can we ever stop imaging in surgically treated and radiotheraphynaive patients with non-functioning pituitary adenoma? Eur $\mathrm{J}$ Endocrinol 2011;165:739-44.

[23] Anagnostis P, Adamidou F, Polyzos SA, Efstathiadou Z, Panagiotou A, Kita M. Non-functioning pituitary adenomas: a single center experience. Exp Clin Endocrinol Diabetes 2011;119:314-9.

[24] Greenman Y. Present and future perspectives for medical theraphy of nonfunctioning pituitary adenomas. Eur J Endocrinol 2017; 177:113-24.

[25] Castinelli F, Dufour H, Gaillard S, Jouanneau E, Vasiljevic A, Villa C, et al. Non-functioning pituitary adenoma: when and how to operate? What pathologic criteria for typing? Ann Endocrinol 2015;7:220-7.

[26] Dehdashti AR, Ganna A, Karabatsou K, GentiliF. Pure endoscopic endonasal approach for pituitary adenomas: early surgical results in 200 patients and comparison with previous microsurgical series. Neurosurgery 2008;62:1006-15.

[27] Losa M, Donofrio CA, Barzaghi R, Mortini P. Presentation and surgical results of incidentally discovered nonfunctioning pituitary adenomas: evidence for a better outcome independently of other patients' characteristic. Eur J Endocrinol 2013;169:735-
42.

[28] Sauer N, Flitsch J, Doeing I, Dannheim V, Burkhardt T, Aberle J. Non-functioning pituitary macroadenomas: benefit from early growth hormone substitution after surgery. Growth Horm IGF Res 2014;24:71-5.

[29] Arafah BM. Medical management of hypopituitarism in patients with pituitary adenomas. Pituitary 2002;5:109-17.

[30] Peters JP, German WJ, Man EB, Welt LG. Functions of gonads, thyroid and adrenals in hypopituitarism. Metabolism 1954;3:118-37.

[31] Dekkers OM, Pereira AM, Romijn JA. Treatment and follow-up of clinially nonfunctioning pituitary macroadenomas. J Clin Endocrinol Metab 2008;93:3717-26.

[32] Ciric I, Ragin A, Baumgardner C, Pierce D. Complications of transsphenoidal surgery: results of a national survey, review the literatüre, and personal experience. Neurosurgery 1997;40:225-36; discussion 236-7.

[33] Kremer P, Forsting M, Ranaei G, Wüster C, Hamer J, Sartor $\mathrm{K}$, et al. Magnetic resonance imaging after transsphenoidal surgery of clinically non-functional pituitary macroadenomas and its impact on detecting residual adenoma. Acta Neurochir (Vienna) 2002;144:433-43.

[34] Bonneville J-F, Cattin F, Bonneville F. Imaging of pituitary adenomas. Presse Med 2009;38:84-91.

[35] Cortet-Rudelli C, Bonneville JF, Borson-Chazot F, Clavier L, Coche Dequéant B, Desailloud R, et al. Post-surgical management of non-functioning pituitary adenoma. Ann Endocrinol (Paris) 2015;76:228-38.

[36] Losa M, Mortini P, Barzaghi R, Ribotto P, Terreni MR, Marzoli SB, et al. Early results of surgery in patients with nonfunctioning pituitary adenoma and analysis of the risk of tumor recurrence. J Neurosurg 2008;108:525-32.

[37] Molitch ME. Pituitary incidentalomas. Best Pract Res Clin Endocrinol Metab 2009;23:667-75.

[38] Tampourlou M, Fountas A, Ntali G, Karavitaki N. Mortality in patients with non-functioning pituitary adenoma. Pituitary 2018;21:203-7.

[39] Hansen TM, Batra S, Lim M, Gallia GL, Burger PC, Salvatori R, et al. Invasive adenoma and pituitary carcinoma: a SEER database analysis. Neurosurg Rev 2014;37:279-85.

\section{ERRATUM}

In the original article "Preoperative and postoperative features of non-functioning pituitary adenomas: a single center experience" published in The European Research Journal, September 2019, vol. 5, Iss. 5, pp. 827-835, the second author is Buket Biçer instead of Buket Özbiçer. 